\title{
ASO Visual Abstract: COVID-19 is Affecting the Presentation and Treatment of Melanoma Patients in the Northeastern United States
}

Catherine H. Davis, MD, MPH ${ }^{1,2}$, Jason Ho, BA ${ }^{2}$, Stephanie H. Greco, MD $^{3}$, Vadim P. Koshenkov, MD ${ }^{1,2}$, Roberto J. Vidri, $\mathrm{MD}^{3}$, Jeffrey M. Farma, $\mathrm{MD}^{3}$, and Adam C. Berger, $\mathrm{MD}^{1,2}$

${ }^{1}$ Division of Surgical Oncology, Rutgers Cancer Institute of New Jersey, New Brunswick, NJ; ${ }^{2}$ Rutgers Robert Wood Johnson University Medical School, New Brunswick, NJ; ${ }^{3}$ Division of Surgical Oncology, Fox Chase Cancer Center, Philadelphia, PA

The recent pandemic has resulted in a shift away from screening and non-urgent medical care. Melanoma patients currently are presenting with more advanced disease, which may have significant downstream effects on their prognosis (https://doi.org/10.1245/s10434-02111086-8).

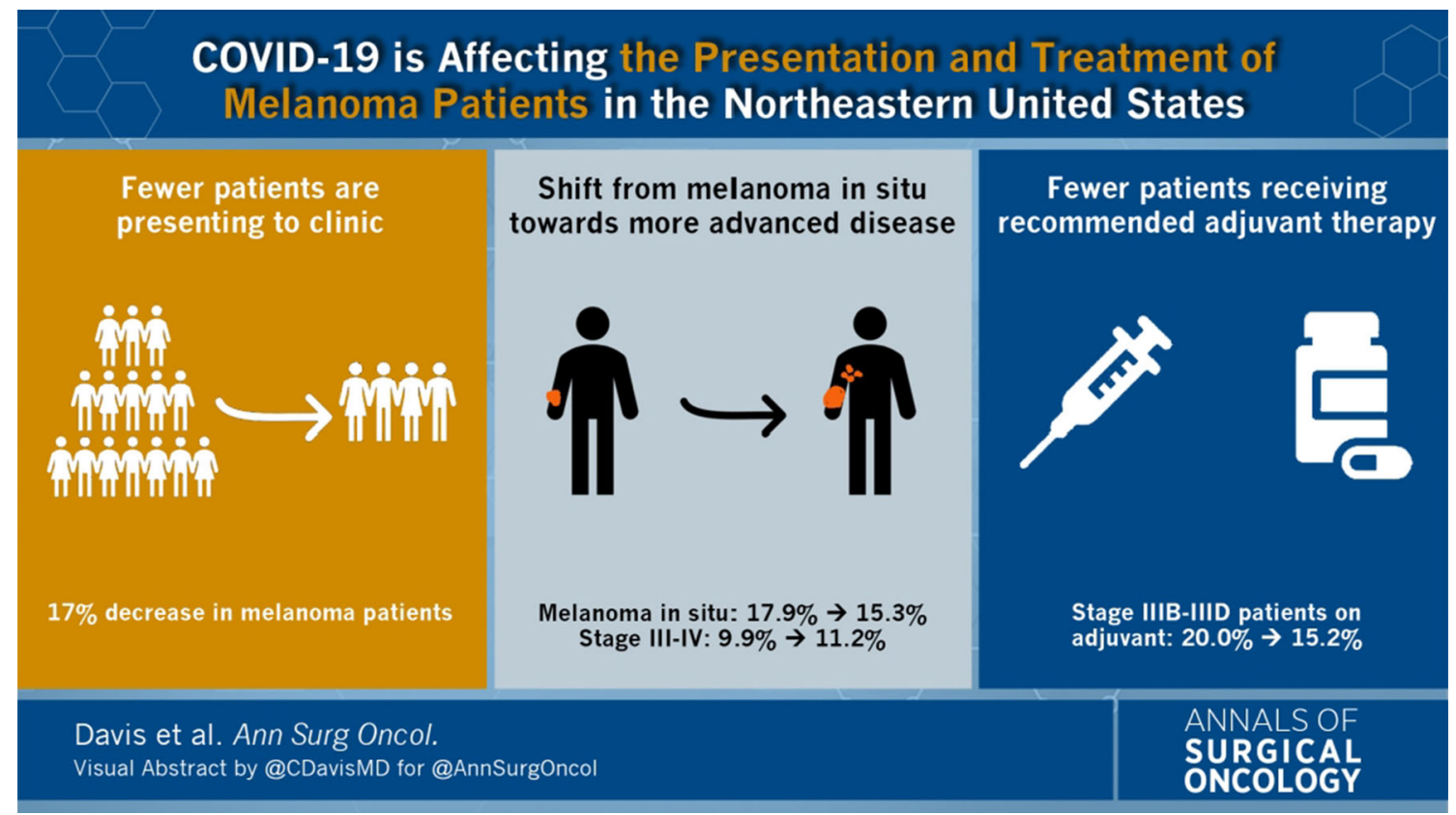

Poster presentation at the Annual Meeting of the Society of Surgical Oncology, March 2021.

(C) Society of Surgical Oncology 2021

A. C. Berger, MD

e-mail: ab2047@cinj.rutgers.edu; adam.berger@rutgers.edu
Publisher's Note Springer Nature remains neutral with regard to jurisdictional claims in published maps and institutional affiliations. 